\title{
Source-water odor during winter in the Yellow River area of China: Occurrence and diagnosis ${ }^{\text {is }}$
}

\author{
Xia Li a, Jianwei Yu ${ }^{\text {a, }}{ }^{*}$, Qingyuan Guo a , Ming Su ${ }^{b}$, Tingting Liu ${ }^{a}$, Min Yang ${ }^{b}$, Yu Zhao ${ }^{c}$ \\ ${ }^{a}$ Key Laboratory of Drinking Water Science and Technology, Research Center for Eco-Environmental Sciences, Chinese Academy of Sciences, Beijing, 100085, \\ China \\ ${ }^{\mathrm{b}}$ State Key Laboratory of Environmental Aquatic Chemistry, Research Center for Eco-Environmental Sciences, Chinese Academy of Sciences, Beijing, 100085, \\ China \\ ${ }^{\mathrm{c}}$ Food and Drug Anti-doping Laboratory, China Anti-Doping Agency, Beijing 100029, China
}

\section{A R T I C L E I N F O}

\section{Article history:}

Received 25 February 2016

Received in revised form

29 June 2016

Accepted 29 June 2016

Available online 12 July 2016

\section{Keywords:}

Taste and odor

Fishy odor

Drinking water

GC $\times$ GC-TOFMS

Yellow River

\begin{abstract}
A B S T R A C T
Yellow River source water has long suffered from odor problems in winter. In this study, odor characteristics, potential odorants, and algae in the source water of six cities (Lanzhou, Yinchuan, Hohhot, Zhengzhou, Jinan and Dongying) along the Yellow River were determined in winter (February to March 2014). According to flavor profile analysis (FPA), moderate to strong fishy odors occurred in all cities, except for Lanzhou. At the same time, mild earthy/musty odors and septic/swampy odors were also detected. The strong fishy odor (FPA intensity, 8.5) in Yinchuan was attributed to the abnormal growth of Dinobryon (cell density, $5.7 \times 10^{4}$ cells $/ \mathrm{mL}$ ), while the fishy odors in Hohhot, Zhengzhou, Jinan, and Dongying might be caused by Melosira and Cyclotella, Cryptomonas, Dinobryon, and Synedra, respectively. Unsaturated aldehydes, which have been reported to cause fishy odors, were not detected in all samples. However, some saturated aldehydes, including hexanal, heptanal, nonanal, decanal, and benzaldehyde, were detected with a total concentration range of $690 \mathrm{ng} / \mathrm{L}$ to $2166 \mathrm{ng} / \mathrm{L}$, and might have partly contributed to the fishy odors. In addition, 2-MIB (5.77-21.12 ng/L) and geosmin (2.26-9.73 ng/L) were responsible for the earthy/musty odors in the Yellow River source waters, and dimethyl disulfide $(648.2 \mathrm{ng} / \mathrm{L})$ was responsible for the rancid/swampy odor (FPA intensity, 8.0) episode in Yinchuan. This is a comprehensive study reporting on the occurrence and possible reasons for the odor issues in the Yellow River source water during winter.
\end{abstract}

(C) 2016 Elsevier Ltd. All rights reserved.

\section{Introduction}

Taste and odor $(\mathrm{T} / \mathrm{O})$ episodes in drinking water have been a recurring problem in many countries (Hayes and Burch, 1989; Izaguirre et al., 1999; Sun et al., 2013). The origins of T/O problems in drinking water are often found in source waters (Izaguirre et al., 1999). The occurrence of T/O episodes is often associated with eutrophic waters during summer or early autumn (Watson, 2003; Li et al., 2010; Ma et al., 2013), such as the well documented earthy/musty odor caused by two algal-derived terpenoids (2-MIB and geosmin) that originate from typical Cyanobacteria (Watson et al., 2000; Lin et al., 2002; Li et al., 2010; Sun et al., 2013) or Actinomycetes (Lanciotti et al., 2003). However, fishy/rancid/oily

\footnotetext{
th This paper has been recommended for acceptance by Dr. Chen Da.

* Corresponding author.

E-mail address: jwyu@rcees.ac.cn (J. Yu).
}

odors have been increasingly reported in some meso-oligotrophic systems during early spring and winter, even with ice-cover present (Burlingame et al., 1992; Naumenko, 1992; Watson et al., 2001). In these cases, $\mathrm{T} / \mathrm{O}$ episodes are commonly associated with the growth of diatoms (Wendel and Juttner, 1996), Chrysophyta (Wee et al., 1994; Watson et al., 2001; Watson and Satchwill, 2003), Cryptophyta and dinoflagellates (Watson et al., 2001). Some unsaturated fatty acid derivatives, such as 2,4-heptadienal, 2,4decadienal, 2,4,7-decatrienal, and 2,6-nonadienal, have been speculated as responsible for such odors (Wee et al., 1994; Khiari et al., 1995; Wendel and Juttner, 1996). Compared with earthy/ musty odors, fishy odor problems are not well understood, and related information and research is still very limited.

The Yellow River is one of the most important water sources in China, especially for those cities along its banks and within its watershed. To cope with the high turbidity of the river water, sand settling reservoirs have been constructed in many cities, which 
have created ideal conditions for algal growth and increased the occurrence of fishy odors during winter. Except for one case study that reported on the abnormal growth of Dinobryon as possibly being responsible for such odor issues (Zhao et al., 2013), information regarding the odor characteristics, potential odorants, and related algae is still unavailable.

In this study, the occurrences of odors and algae in source waters of six cities (Lanzhou, Yinchuan, Hohhot, Zhengzhou, Jinan, and Dongying) along the Yellow River in China were determined during winter (February to March 2014). Flavor profile analysis (FPA) was used to characterize the odor profiles of source water, and twodimensional (2D) gas chromatography with time-of-flight mass spectrometry (GC $\times$ GC-TOFMS), an analytical instrument with high resolution, sensitivity, and separation capacity (Chin et al., 2011; da Silva et al., 2014), was used to simultaneously determine 16 specific odorants. The results of this study will provide useful knowledge for the better control of odor problems in the Yellow River source waters.

\section{Methods and materials}

\subsection{Study sites and sampling}

This study was conducted from February to March 2014. Six cities along the Yellow River, including Lanzhou, Yinchuan, Hohhot, Zhengzhou, Jinan, and Dongying, were selected for study, as shown in Fig. 1. Except for Lanzhou, each city has a sand settling reservoir to reduce the high turbidity of the river water. Raw water samples were taken from the reservoirs at $0-0.5 \mathrm{~m}$ under the water surface. The samples from Lanzhou were directly taken from the river. Triplicate samples were collected in $500 \mathrm{~mL}$ amber bottles, with $5 \mathrm{~mL}$ Lugol's solution added in one bottle for algal fixation and $5 \mathrm{~mL}$ $\mathrm{HgCl}_{2}$ solution added in the other two bottles for FPA evaluation and odorant quantification. All samples were stored in thermotanks with ice bags and delivered to the laboratory as soon as possible. Typical water quality parameters are shown in Table 1.

\subsection{Chemicals and reagents}

Sixteen odor reference standards (purity $>95 \%$ ), including two terpenoids (2-MIB, geosmin), four sulfides (dimethyl sulfide, dimethyl disulfide, dimethyl trisulfide, and diethyl disulfide) and ten aldehydes (hexanal, heptanal, nonanal, decanal, and benzaldehyde, 2-octenal, $\beta$-cyclocitral, 2,4-heptadienal, 2,6-nonadienal, and 2,4-decadienal), were purchased from Sigma-Aldrich (USA), with stock solutions of $100 \mathrm{mg} / \mathrm{L}$ stored in methanol. Detailed information on the 16 odorous compounds is shown in Table 2. Analytical grade $\mathrm{NaCl}, \mathrm{KI}, \mathrm{HgCl}_{2}$, and $\mathrm{Na}_{2} \mathrm{SO}_{4}$ were obtained from Beijing Chemicals Ltd., China. Both $\mathrm{NaCl}$ and $\mathrm{Na}_{2} \mathrm{SO}_{4}$ were heated at $450{ }^{\circ} \mathrm{C}$ for $2 \mathrm{~h}$ before use. Ultrapure water $(18.2 \mathrm{M} \Omega \mathrm{cm})$ was produced with a Milli-Q purification system.

\subsection{Sample pre-concentration}

Sample pre-concentration was performed using liquid-liquid extraction as follows: $500 \mathrm{~mL}$ water samples were filtered through $1.2 \mu \mathrm{m}$ glass fiber filters prior to liquid-liquid extraction, and extracted twice using dichloromethane as the extracting solvent with a volume of $50 \mathrm{~mL}$ and $25 \mathrm{~mL}$, respectively. Dehydration was then carried out with $\mathrm{Na}_{2} \mathrm{SO}_{4}$. Samples were concentrated to a final volume of $100 \mu \mathrm{L}$ by rotary evaporation and under a gentle stream of nitrogen. The overall concentration factor was 5000. All pre-concentrated samples were stored at $-20{ }^{\circ} \mathrm{C}$ prior to analysis.

\subsection{Odor evaluation}

The odor characteristics of water samples were evaluated by FPA. A detailed description of the training and application procedures can be found in the Standard Methods for Water and Wastewater (APHA, 2005). Namely, four non-smokers with normal olfactory function and no known anosmia were selected as the panelists in this study. Seven-point scales of 1-12 were used to describe the intensity of samples (1: odor threshold, 2-4: weak odor intensity, 6-8: moderate odor intensity, 10-12: strong odor intensity). The evaluation was conducted immediately on the day samples were received. Each panelist gave the evaluation of odor characteristics and intensity, respectively, which were then averaged and used as the final evaluation result.

\subsection{GC $\times$ GC-TOFMS analysis}

A 2D gas chromatograph with time-of-flight mass spectrometer (LECO, USA), equipped with a multipurpose sampler (Gerstel, Germany), was used for odorant analysis. The GC was equipped with an Rxi-5silv column (30 m $\times 0.25 \mathrm{~mm}$ i.d. $\times 0.25 \mu \mathrm{m}$ film thickness, Restek, USA) and a secondary Rxi-17 column ( $1.79 \mathrm{~m} \times 0.1 \mathrm{~mm}$ i.d. $\times 0.1 \mu \mathrm{m}$ film thickness, Restek, USA). Sample extracts $(1 \mu \mathrm{L})$ were injected into the $\mathrm{GC} \times \mathrm{GC}$-TOFMS in splitless mode with an inlet temperature of $250{ }^{\circ} \mathrm{C}$. The carrier gas was ultrapure helium at $1.0 \mathrm{~mL} / \mathrm{min}$. The temperature program of the first column was: $40{ }^{\circ} \mathrm{C}$ for $0.2 \mathrm{~min}$, then raised by $4^{\circ} \mathrm{C} / \mathrm{min}$ to $280^{\circ} \mathrm{C}$, and finally maintained at $280{ }^{\circ} \mathrm{C}$ for $5 \mathrm{~min}$. The temperature of the second oven was programmed at $45^{\circ} \mathrm{C}$ for $0.2 \mathrm{~min}$, then raised by $5^{\circ} \mathrm{C} / \mathrm{min}$ to $285^{\circ} \mathrm{C}$, and maintained at $285^{\circ} \mathrm{C}$ for $5 \mathrm{~min}$. The separation time of the second dimension was $5.0 \mathrm{~s}$, including $1.5 \mathrm{~s}$ for a cold pulse time and $1.0 \mathrm{~s}$ for a hot pulse time. The transfer line linking the secondary oven with the mass spectrometer was maintained at $250{ }^{\circ} \mathrm{C}$. The MS detector was operated in full-scan mode ( $\mathrm{m} / \mathrm{z} 50-500)$, with a data acquisition rate of 100 spectra/s. The odorant concentrations were determined by external standard methods. Every water sample batch was analyzed in duplicate, and the odorant concentrations were the average values of the parallel analyses. In this study, 16 typical odorants were selected for quantification. The methodology used was developed in our previous study (Guo et al., 2015), the accuracy and precision of which was satisfactory.

\subsection{Algal enumeration}

Algal taxa and cell counts were performed with a $1 \mathrm{~mL}$ phytoplankton counter chamber using a microscope (BX 51 Olympus, Japan) under a $20 \times$ objective lens. For the samples with high cell density, cell numbers were counted without concentration. For other samples, cell numbers were counted after $10 \times$ preconcentration (from $100 \mathrm{~mL}$ to $10 \mathrm{~mL}$ ) by settling in Lugol's solution, and triplicate $1 \mathrm{~mL}$ concentrated samples were collected separately and counted. Algae were identified to genera or to species based on morphological observation, as Su et al. (2014) indicated.

\section{Results and discussion}

\subsection{Odor characteristics}

The odor characteristics of the water samples were evaluated by FPA, as shown in Table 3. The source water from Yinchuan exhibited strong fishy and rancid/swampy odors, while samples from Hohhot, Zhengzhou, Jinan, and Dongying were described as having moderately fishy or related odors. No fishy odor was perceived in 


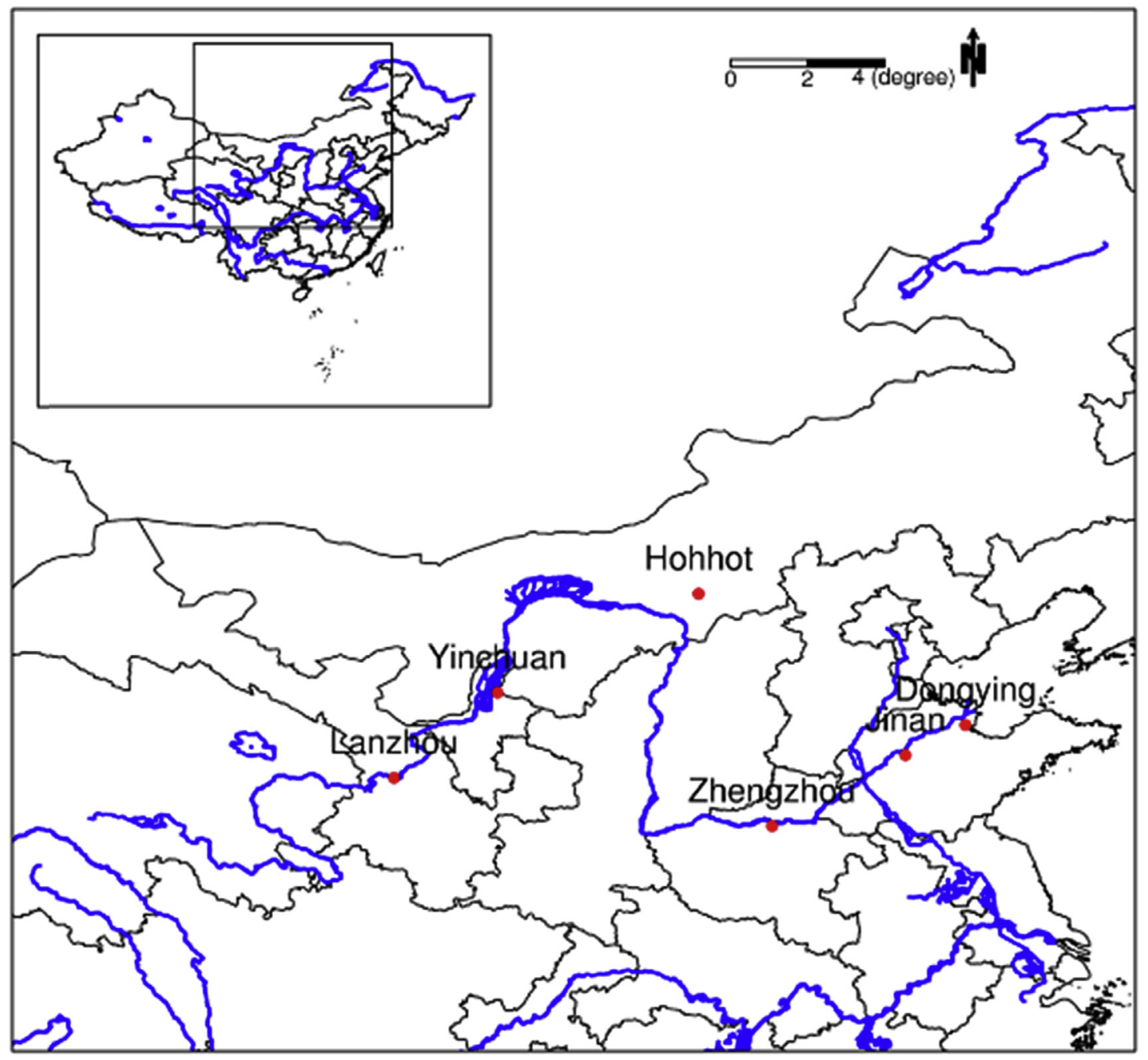

Fig. 1. Sampling sites (Lanzhou, Yinchuan, Hohhot, Zhengzhou, Jinan, Dongying).

Table 1

Water quality parameters.

\begin{tabular}{|c|c|c|c|c|c|c|}
\hline Water quality parameters & Lanzhou & Yinchuan & Hohhot & Zhengzhou & Jinan & Dongying \\
\hline Water Temperature $/{ }^{\circ} \mathrm{C}$ & 5.0 & 1.5 & 2.5 & 8.0 & 7.0 & 9.4 \\
\hline $\mathrm{pH}$ & 8.1 & 7.66 & 7.7 & 8.19 & 8.32 & 8.68 \\
\hline $\mathrm{TOC} /\left(\mathrm{mg} \mathrm{L}^{-1}\right)$ & 1.92 & 2.15 & 3.21 & 2.78 & 2.86 & 2.96 \\
\hline $\mathrm{TN} /\left(\mathrm{mg} \mathrm{L}^{-1}\right)$ & 2.51 & 2.29 & 4.68 & 5.51 & 4.40 & 3.61 \\
\hline $\mathrm{TP} /\left(\mathrm{mg} \mathrm{L}^{-1}\right)$ & 0.049 & 0.021 & 0.093 & 0.078 & 0.039 & 0.036 \\
\hline
\end{tabular}

the sample from Lanzhou, but a slightly septic/swampy odor was detected. A previous investigation on the occurrence of odor in major cities across China showed that river source waters tend to exhibit pollution-origin odors, while lake/reservoir source waters tend to exhibit algae-origin odors (Sun et al., 2014). Among the six cities, only Lanzhou takes water directly from the Yellow River without a reservoir, which might be the main reason for the lack of fishy odor in the source water. In addition to the fishy and septic/ swampy odors, all water samples exhibited mild earthy/musty odors with an FPA intensity ranging from 4 to 6 , except for Yinchuan.

\subsection{Algal population characteristics}

Table 4 shows the algal population characteristics in the six source waters. Chrysophyta, Cryptophyta, and diatoms were the dominant algae during winter. Some members in these phyla, including Dinobryon, Cryptomonas, Asterionella, Melosira, Synedra, and Cyclotella, reportedly contain high intracellular unsaturated and polyunsaturated fatty acids associated with fishy/oily/cucumber odors in water (Watson, 2004). It could be speculated that the fishy odors in the Yellow River might be associated with the presence of these species. Similar to odor threshold concentrations (OTCs), critical cell density (CDC), defined as the minimum algal density at which people can perceive odor or algal capita VOC production exceeding its OTCs, is sometimes used as a criterion to evaluate the potential impact of algal species on aquatic odor levels. Watson (2010) summarized CDCs for Dinobryon $\left(3 \times 10^{3}\right.$ to $4 \times 10^{5}$ cells $\left./ \mathrm{mL}\right)$, Asterionella $\left(3 \times 10^{3}\right.$ cells $\left./ \mathrm{mL}\right)$, Cyclotella $\left(2 \times 10^{3}\right.$ cells $\left./ \mathrm{mL}\right)$, Melosira $\left(3 \times 10^{3}\right.$ cells $\left./ \mathrm{mL}\right)$, Synedra 
Table 2

Information of the odorous compounds.

\begin{tabular}{|c|c|c|c|c|c|}
\hline category & Compounds & Odor description & OTC $^{\mathrm{a}}(\mu \mathrm{g} / \mathrm{L})$ & CAS & Detection limits $(\mathrm{ng} / \mathrm{L})$ \\
\hline \multirow[t]{2}{*}{ Terpenoids } & MIB & Earthy, musty & 0.01 & $2371-42-8$ & 0.47 \\
\hline & Geosmin & Earthy, musty & 0.004 & $19700-21-1$ & 0.83 \\
\hline \multirow[t]{4}{*}{ Sulfides } & Dimethyl sulfide & Rotten cabbage & 1 & $75-18-3$ & 1.26 \\
\hline & Dimethyl disulfide & Septic, garlic, putrid & 0.03 & $624-92-0$ & 2.23 \\
\hline & Dimethyl trisulfide & garlic, putrid, swampy & 0.01 & $3658-80-8$ & 0.77 \\
\hline & Diethyl disulfide & Rancid, foul smell & 0.02 & $110-81-6$ & 0.02 \\
\hline \multirow[t]{10}{*}{ Aldehydes } & Hexanal & Grassy, fatty & 4.5 & $66-25-1$ & 1.42 \\
\hline & Heptanal & Fishy, oily & 3 & $111-71-7$ & 6.29 \\
\hline & Nonanal & Fruity, fragrance & 1 & $124-19-6$ & 0.43 \\
\hline & Decanal & Orange flavor & 3 & $112-31-2$ & 13.75 \\
\hline & Benzaldehyde & almond & 4.5 & $100-52-7$ & 10.87 \\
\hline & 2-Octenal & Green-leafy, orange & n.a. & $2548-87-0$ & 8.33 \\
\hline & 2,4-Heptadienal & Fishy, oily & 5 & 4313-03-5 & 70.55 \\
\hline & 2,6-Nonadienal & Grassy; cucumber & 0.08 & $17587-33-6$ & 60.61 \\
\hline & 2,4-Decadienal & Fishy, rancid & 0.029 & $2363-88-4$ & 9.21 \\
\hline & $\beta$-Cyclocitral & Hay/grassy, tobacco/smoky & 500 & $432-25-7$ & 3.35 \\
\hline
\end{tabular}

a Odor threshold concentration in water (cited from Guo et al., 2015).

Table 3

FPA evaluation of the Yellow River source water samples.

\begin{tabular}{llll}
\hline Sampling sites & Odor descriptor & Intensity $^{\mathrm{a}}$ & Panelists $^{\mathrm{b}}$ \\
\hline Lanzhou & Earthy/musty & 4.5 & $4 / 4$ \\
\multirow{3}{*}{ Yinchuan } & septic/swampy & 2.7 & $3 / 4$ \\
& septic/swampy & 8.0 & $4 / 4$ \\
Hohhot & fishy & 8.5 & $4 / 4$ \\
\multirow{3}{*}{ Zhengzhou } & Earthy/musty & 5.5 & $4 / 4$ \\
\multirow{2}{*}{ Jinan } & fishy & 4.5 & $4 / 4$ \\
& Earthy/musty & 6.0 & $4 / 4$ \\
Dongying & fishy & 4.0 & $3 / 4$ \\
& Earthy/musty & 4.0 & $4 / 4$ \\
& Algae/fishy & 2.7 & $3 / 4$ \\
& Earthy/musty & 3.5 & $4 / 4$ \\
\hline
\end{tabular}

${ }^{a}$ Intensity rating scale: 0 for odor-free; 2,4 for weak; 6,8 for moderate; 10,12 for strong. Reported intensity value here was the average of the panelists.

$\mathrm{b}$ Numbers of the panelist reporting the odor characteristics. presence might have enhanced the fishy odor produced by Synedra.

The potential contribution of each algal species to overall odor was further discussed according to the detailed algal data shown in Table 4. There was an outbreak of Dinobryon in Yinchuan at a cell intensity of $5.7 \times 10^{4}$ cells $/ \mathrm{mL}$, which was one order of magnitude higher than its CDC value. Previous studies have reported that Dinobryon is likely to be more abundant at low temperatures (Naumenko, 1992; Agbeti and Smol, 1995) and accompanied with the occurrence of significant fishy odors (Rashash et al., 1995; Watson et al., 2001; Satchwill et al., 2007; Zhao et al., 2013). Thus, the strong fishy odor in Yinchuan could be associated with the abnormal growth of Dinobryon. Similar conclusions could also be drawn for the Jinan source water, which had lower concentrations of Dinobryon and weaker fishy odors. Diatoms were the predominant algae in Lanzhou (Asterionella), Hohhot (Melosira and Cyclotella), Zhengzhou (Melosira and Cyclotella), and Dongying

Table 4

Algal taxa and cell number $\left(\times 10^{3}\right.$ cells/L).

\begin{tabular}{|c|c|c|c|c|c|c|c|c|}
\hline \multirow[t]{2}{*}{ Sampling sites } & \multirow[t]{2}{*}{ Total } & \multirow{2}{*}{$\frac{\text { Cryptophyta }}{\text { Dinobryon }}$} & \multirow{2}{*}{$\frac{\text { Chrysophyta }}{\text { Cryptomonas }}$} & \multicolumn{4}{|l|}{ Diatom } & \multirow[t]{2}{*}{ Others } \\
\hline & & & & Asterionella & Melosira & Synedra & Cyclotella & \\
\hline Lanzhou & 596 & 0 & 0 & 564 & 8 & 4 & 4 & 16 \\
\hline Yinchuan & 58,540 & 57,056 & 0 & 372 & 48 & 260 & 756 & 48 \\
\hline Hohhot & 2068 & 12 & 0 & 96 & 1040 & 112 & 768 & 40 \\
\hline Zhengzhou & 616 & 16 & 240 & 0 & 152 & 16 & 108 & 84 \\
\hline Jinan & 728 & 532 & 0 & 0 & 48 & 4 & 92 & 52 \\
\hline Dongying & 3306 & 32 & 16 & 0 & 220 & 1336 & 480 & 1222 \\
\hline
\end{tabular}

$\left(3 \times 10^{3}\right.$ cells $\left./ \mathrm{mL}\right)$, and Cryptomonas $\left(1 \times 10^{3}\right.$ cells $\left./ \mathrm{mL}\right)$, and, although these CDC values might be misleading for several reasons, they can be used as general guidelines for preliminary assessment of water quality.

In this study, the ratio of algal cell number to CDC values for the six typical fishy odor producing algae at each sampling site were calculated, as shown in Fig. 2. Fishy odor intensity generally exhibited an increasing trend with the increase in algal cell number/CDC value, suggesting that the fishy odor in the source waters might be associated with these algae. Dongying exhibited a slightly different result, that is, high fishy odor intensity, but relatively low algal cell number/CDC value. This might be associated with the high density of Chlorophyta (expressed as "others" in Table 4). Chlorophyta is not a typical fishy odor producing genera, but is commonly associated with "grassy" odors (Watson, 2010). Its
(Synedra). Asterionella was the only predominant algae in Lanzhou, with a cell number less than one fifth of the CDC value (algal cell number/CDC value, 0.19), which was in accordance with the FPA evaluation results. The cell densities of Melosira (1040 cells/mL) and Cyclotella (768 cells/mL) in Hohhot reached a third and a half of their respective $\mathrm{CDC}$ values, with a total algal cell number/CDC value of 0.8 , suggesting that these two algae might have contributed to the mild fishy odor detected. As discussed above, the presence of Synedra (1336 cells/mL) in Dongying, together with Chlorophyta (1222 cells/mL), might be responsible for its seaweed/ fish-like odors. In Zhengzhou, the coexistence of Cryptomonas, Melosira, and Cyclotella was observed with a total algal cell number/ $\mathrm{CDC}$ value of 0.35 . These three algal species might have contributed to the occurrence of the mild fishy odor detected. However, to clarify algal contribution to the fishy odor, isolation of algal species 


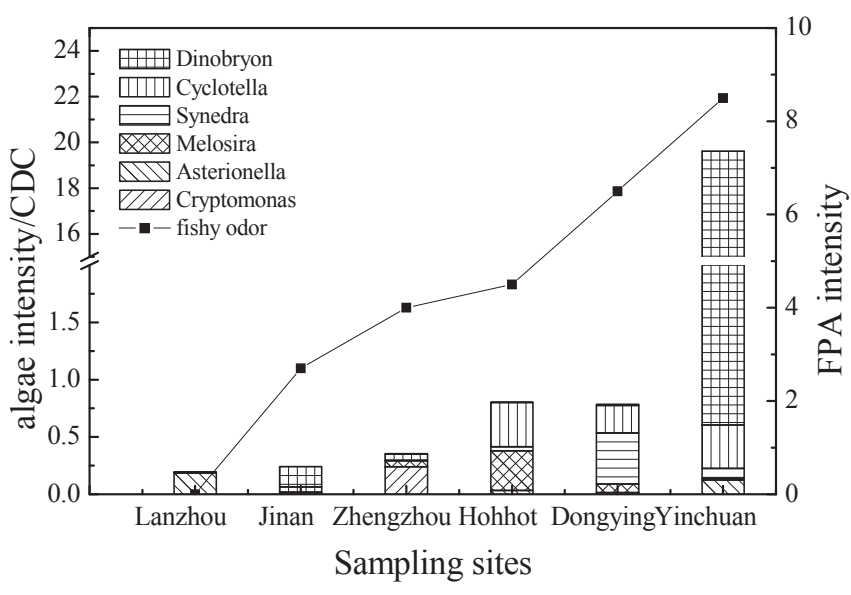

Fig. 2. The ratio of algal cell number to $C D C$ value in contrast with fishy odor intensity at each sampling site.

is required in future study.

\subsection{Evaluation of typical odorous compounds}

GC $\times$ GC-TOFMS was used to detect the potential odorants in the six water samples, and the results are shown in Fig. 3. The distribution of aldehydes detected in the Yellow River source water is shown in Fig. 3 (a). Some typical polyunsaturated fatty acid (PUFA) derivatives, including 2,4-heptadienal, 2,6-nonadienal, and 2,4decadienal, are reportedly associated with fishy/oily/cucumber odors (Rashash et al., 1997; Hartvigsen et al., 2000). According to previous studies, Dinobryon (Watson et al., 2001; Zhao et al., 2013), Melosira (Wendel and Juttner, 1996), Synura (Wee et al., 1994), and Uroglena (Watson and Satchwill, 2003) can produce these unsaturated aldehydes. Despite Dinobryon and Melosira being found in some source water samples, none of the above compounds were detected. In our previous study (Zhao et al., 2013), 2,4-heptadienal and 2,4-dicadienal were detected during a fishy odor episode in the same region. Production of these PUFA derivatives is usually triggered by the loss of cell integrity and degradation of PUFAs during cell damage or death, which might be affected by abrupt environmental changes, such as salinity and temperature (Watson et al., 2001, 2003). Thus, the reason for the non-detection of unsaturated aldehydes needs to be explored in future study.

Saturated aldehydes, including hexanal, heptanal, nonanal, decanal, and benzaldehyde, were detected at concentration ranges of 59.47-264.62 ng/L, 51.35-191.53 ng/L, 256.31-1027.5 ng/L, 36.60-209.35 ng/L, and 213.40-476.15 ng/L, respectively. Heptanal, which can be produced by Synura uvella and Cryptomonas ovata var. palustris, has long been linked to fishy/oily/pungent odors, while hexanal, decanal, 2-octanal, and nonanal are linked to cucumber/ grassy/waxy/pungent odors (Collins and Kalnins, 1965; Jüttner, 1981; Cotsaris et al., 1995). The concentrations of these aldehydes were all lower than their respective OTCs. Odor activity values (OAVs), which are calculated by dividing the concentration of odorous compounds by their odor threshold value (Jelen et al., 2013), can be employed to evaluate the contribution of different odorants to an odor profile. The OAVs for the detected aldehydes were all below 0.15, except for nonanal (0.20-1.03), which is reportedly associated with fruity odor (Cotsaris et al., 1995), indicating that these compounds might have less impact on fishy odors. However, Rashash et al. (1997) revealed that interferences (e.g. masking, antagonism, or synergism) exist among compound mixtures, and subthreshold concentrations of some odorous

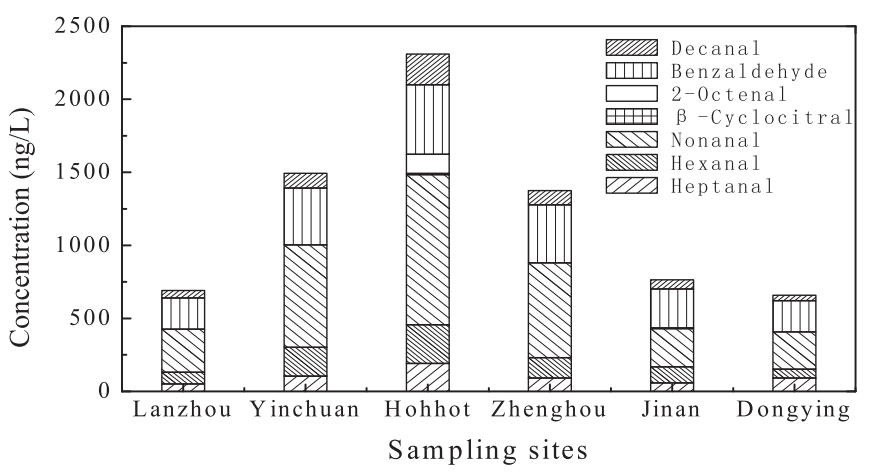

(a)

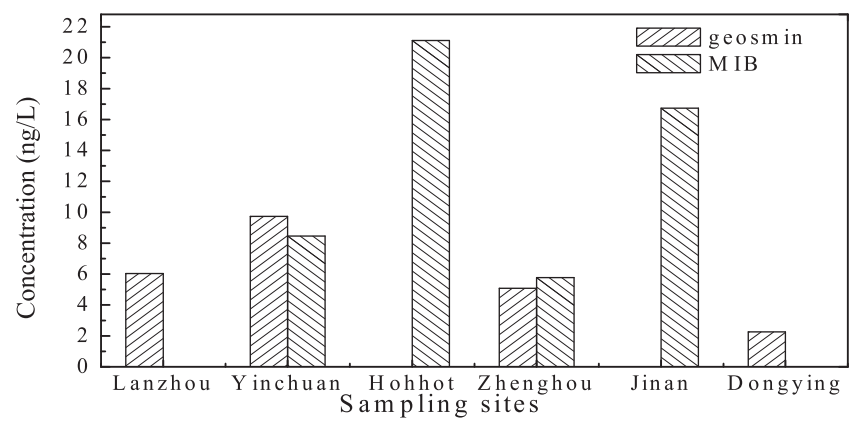

(b)

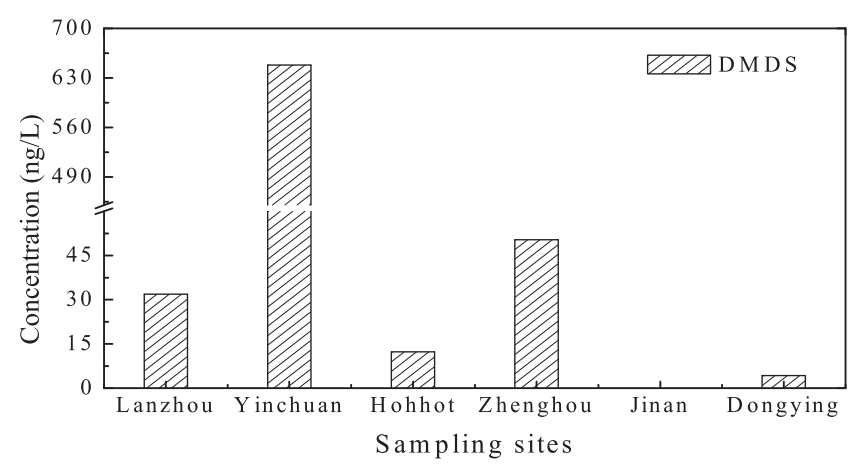

(c)

Fig. 3. Distribution of odorous compounds at different sampling sites: (a) aldehydes; (b) geosmin and MIB; (c) sulfides.

compounds may contribute to overall perception. This combined effect has also been found in many other studies. Venkateshwarlu et al. (2004) identified six potent odorants in fish oil enriched milk, and presumed that the fishy odor was the combination of these odorants as none of the separated individual odorants imparted a fishy odor. Marsili and Laskonis (2014) reported synergy effects between heptanal and (E, Z)-3, 5-octadien-2-one produced by marine algae. Therefore, even though the levels of these aldehydes were lower than their respective OTCs, co-existence of these compounds and other unknown ones might have contributed to the overall fish-like odors. Notably, some amines, such as butanolamine, ethanolamine, methylamine, and trimethylamine, are thought to be associated with fishy odors in the aquatic environment (Watson, 2010). These amines have low OTCs and can be formed through the bacterial degradation of some amino acids in water (Mallevialle and Suffet, 1987). Some potent amines have been detected in cultures of algae like Cyanobacteria, Chlorophyta, and 


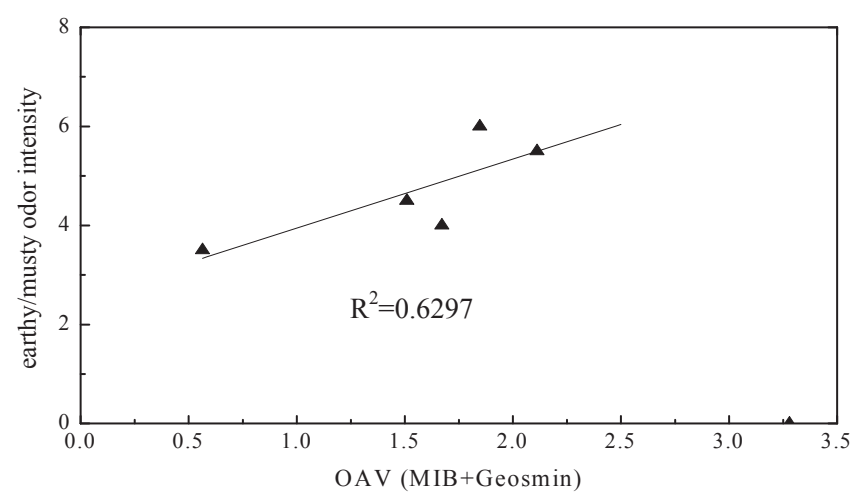

Fig. 4. Correlation between earthy/musty odor intensity and OAV of MIB and geosmin.

Chrysophyta (Herrmann and Jüttner, 1997; Pohnert and von Elert, 2000). As a major river source across several provinces in China, the Yellow River is often contaminated by domestic sewage and industrial wastewater. Thus, the contribution of amines to fishy odors should be further evaluated.

As shown in Fig. 3 (b), geosmin was the only earthy/musty odor causing compound detected in Lanzhou (6.04 ng/L) and Dongying $(2.26 \mathrm{ng} / \mathrm{L})$ source water samples; 2-MIB was only detected in Hohhot (21.12 ng/L) and Jinan (16.72 ng/L); and both geosmin and 2-MIB were detected in Yinchuan and Zhengzhou. The earthy/ musty odor intensity had a positive correlation with the sum of the OAVs of 2 -MIB and geosmin $\left(\mathrm{R}^{2}=0.6297, \mathrm{P}<0.05\right)$, as shown in Fig. 4. One exception was that no earthy/musty odor was perceived in Yinchuan, despite the relatively high concentrations of 2-MIB and geosmin. This might be attributed to the masking action of the earthy/musty odor by the strong fishy or rancid/swampy ones. Guo et al. (2016) also reported similar results in which relatively high intensity septic/swampy odor caused by dimethyl disulfide and diethyl disulfide suppressed the earthy/musty odor caused by 2-MIB and geosmin. Up to now, Cyanobacteria are the only known producers of 2-MIB and geosmin among algae (Watson, 2010). Actinomycetes, which can grow in autumn and winter (Lanciotti et al., 2003), might be responsible for the production of these earthy/musty odor causing compounds. Actinomycetes might also enter freshwater systems via terrestrial runoff, and subsequently cause T/O outbreaks in drinking water (Zaitlin et al., 2003).

Among the four sulfides analyzed, dimethyl disulfide, which can cause swampy/septic/sulfurous odors (Yang et al., 2008; Yu et al., 2009), was the only one detected in the source water samples. As shown in Fig. 3 (c), the concentrations of dimethyl disulfide in Lanzhou, Yinchuan, and Dongying exceeded the OTCs (30 ng/L), and the corresponding OAVs were also higher than 1 . The highest value was detected in the source water of Yinchuan $(648.2 \mathrm{ng} / \mathrm{L}, \mathrm{OAV}$ 21.6), which agreed with the strong rancid/swampy odor perceived by FPA. Dimethyl disulfide is reportedly associated with the anoxic or anaerobic decomposition of some proteins or amino acids from algae (Ma et al., 2013; Zhang et al., 2013) or other organisms (Franzmann et al., 2001; Yang et al., 2008; Yu et al., 2009).

It is worth noting that some typical fishy odorants were not detected in this study. Though some saturated aldehydes were detected, their contributions to fishy odors were not identified. Further effort should be devoted to the identification of the fishy compounds and evaluation of the contribution of saturated aldehydes to fishy odors.

\section{Conclusions}

The present study demonstrated that most of the Yellow River source water samples exhibited moderate to strong fishy odors, as well as mild earthy/musty odors and septic/swampy ones during winter. The strong fishy odor episode in Yinchuan was attributed to the abnormal growth of Dinobryon $\left(5.7 \times 10^{7}\right.$ cells/L). The fishy odors in Hohhot, Zhengzhou, Jinan, and Dongying might be caused by Melosira and Cyclotella, Cryptomonas, Dinobryon, and Synedra, respectively. Aldehydes, including hexanal, heptanal, nonanal, decanal, and benzaldehyde, might have partly contributed to the fishy odors. Both 2-MIB and geosmin were responsible for the earthy/musty odors in the Yellow River source water, whereas dimethyl disulfide was mainly responsible for the rancid/swampy odors. Future research should focus on the fishy odor causing compounds and their origins.

\section{Acknowledgement}

This study was supported by the National Natural Science Foundation of China (No. 21377144), the Major Science and Technology Program for Water Pollution Control and Treatment (No. 2015ZX07406001), and the "135" Major Project of the Research Center for Eco-Environment Science (YSW2013A02).

\section{References}

Agbeti, M.D., Smol, J.P., 1995. Chrysophyte population and encystment patterns in two Canadian lakes. J. Phycol. 31 (1), 70-78.

APHA, 2005. Standard Methods for the Examination of Water and Wastewater. American Public Health Association.

Burlingame, G.A., Muldowney, J.J., Maddrey, R.E., 1992. Cucumber flavor in Philadelphia drinking-water. J. Am. Water Works. Assoc. 84 (8), 92-97.

Chin, S.T., Eyres, G.T., Marriott, P.J., 2011. Identification of potent odourants in wine and brewed coffee using gas chromatography-olfactometry and comprehensive two-dimensional gas chromatography. J. Chromatogr. A 1218 (42), 7487-7498.

Collins, R.P., Kalnins, K., 1965. Volatile constituents produced by the alga Symura petersenii. ii. Alcohols, esters and acids. Air Water Pollut. 9, 501-504.

Cotsaris, E., Bruchet, A., Mallevialle, J., Bursill, D., 1995. The identification of odorous metabolites produced from algal monocultures. Water Sci. Technol. 31, 251-258.

da Silva, J.M., Machado, M.E., Maciel, G.P.S., Dal Molin, D., Caramao, E.B., 2014. Speciation of nitrogen-containing compounds in an unfractionated coal tar sample by comprehensive two-dimensional gas chromatography coupled to time-of-flight mass spectrometry. J. Chromatogr. A 1373, 159-168.

Franzmann, P.D., Heitz, A., Zappia, L.R., Wajon, J.E., Xanthis, K., 2001. The formation of malodorous dimethyl oligosulphides in treated groundwater: the role of biofilms and potential precursors. Water Res. 35 (7), 1730-1738.

Guo, O.Y., Li, X., Yu, J.W., Zhang, H.F., Zhang, Y., Yang, M., Lu, N., Zhang, D., 2015. Comprehensive two-dimensional gas chromatography with time-of-flight mass spectrometry for screening of potent swampy/septic odor causing compounds in two drinking water sources of China. Anal. Methods 7 (6), 2458-2468.

Guo, Q.Y., Yu, J., Yang, K., Wen, X., Zhang, H., Yu, Z., Li, H., Zhang, D., Yang, M., 2016. Identification of complex septic odorants in Huangpu River source water by combining the data from gas chromatography-olfactometry and comprehensive two-dimensional gas chromatography using retention indices. Sci. Total Environ. 556, 36-44.

Hartvigsen, K., Lund, P., Hansen, L.F., Holmer, G., 2000. Dynamic headspace gas chromatography/mass spectrometry characterization of volatiles produced in fish oil enriched mayonnaise during storage. J. Agric. Food Chem. 48 (10), 4858-4867.

Hayes, K.P., Burch, M.D., 1989. Odorous compounds associated with algal bloom in south Australian waters. Water Res. 23 (1), 115-121.

Herrmann, V., Jüttner, F., 1997. Excretion products of algae. Identification of biogenesis amines by gas-liquid chromatography and mass spectrometry of their trifluoroacetamides. Anal. Biochem. 78, 365-373.

Izaguirre, G., Taylor, W.D., Pasek, J., 1999. Off-flavor problems in two reservoirs, associated with planktonic Pseudanabaena species. Water Sci. Technol. 40 (6), 85-90.

Jelen, H., Majcher, M., Ginja, A., Kuligowski, M., 2013. Determination of compounds responsible for tempeh aroma. Food Chem. 141 (1), 459-465.

Jüttner, F., 1981. Detection of lipid degradation products in the water of a reservoir during a bloom of Synura uvella. Appl. Environ. Microbiol. 41, 100-106.

Khiari, D., Suffet, I.H., Barrett, S.E., 1995. The determination of compounds causing fishy/swampy odors in drinking-water supplies. Water Sci. Technol. 31 (11), 105-112.

Lanciotti, E., Santini, C., Lupi, E., Burrini, D., 2003. Actinomycetes, cyanobacteria and algae causing tastes and odours in water of the River Arno used for the water Supply of Florence. J. Water Supply. Res. Technol. 52 (7), 489-500.

Li, Z.L., Yu, J.W., Yang, M., Zhang, J., Burch, M.D., Han, W., 2010. Cyanobacterial 
population and harmful metabolites dynamics during a bloom in Yanghe Reservoir, North China. Harmful Algae 9 (5), 481-488.

Lin, T.F., Wong, J.Y., Kao, H.P., 2002. Correlation of musty odor and 2-MIB in two drinking water treatment plants in South Taiwan. Sci. Total. Environ. 289 (1-3), 225-235.

Mallevialle, J., Suffet, I., 1987. Identification and Treatment of Tastes and Odors in Drinking Water. AWWA, Denver, Colo.

Marsili, R.T., Laskonis, C.R., 2014. Odorant synergy effects as the cause of fishy malodors in algal marine oils. J. Agric. Food Chem. 62 (40), 9676-9682.

Ma, Z.M., Niu, Y., Xie, P., Chen, J., Tao, M., Deng, X.W., 2013. Off-flavor compounds from decaying cyanobacterial blooms of Lake Taihu. J. Environ. Sci. 25 (3), 495-501.

Naumenko, Y.V., 1992. Chrysophytes of the middle stream of the Ob River. Sib. Biol. Zhurnal 0 (5), 76-81.

Pohnert, G., von Elert, E., 2000. No ecological relevance of trimethylamine in fishDaphnia interactions. Limnol. Oceanogr. 45, 1153-1156.

Rashash, D.M.C., Dietrich, A.M., Hoehn, R.C., 1997. FPA of selected odorous compounds. J. Am. Water Works. Assoc. 89 (4), 131-141.

Rashash, D.M.C., Dietrich, A.M., Hoehn, R.C., Parker, B.C., 1995. The influence of growth-conditions on odor-compound production by two chrysophytes and two cyanobacteria. Water Sci. Technol. 31 (11), 165-172.

Satchwill, T., Watson, S.B., Dixon, E., 2007. Odourous algal-derived alkenes: differences in stability and treatment responses in drinking water. Water Sci. Technol. 55 (5), 95-102.

Su, M., An, W., Yu, J.W., Pan, S.L., Yang, M., 2014. Importance of underwater light field in selecting phytoplankton morphology in a eutrophic reservoir. Hydrobiologia 724 (1), 203-216.

Sun, D.L., Yu, J.W., An, W., Yang, M., Chen, G.G., Zhang, S.J., 2013. Identification of causative compounds and microorganisms for musty odor occurrence in the Huangpu River, China. J. Environ. Sci. 25 (3), 460-465.

Sun, D.L., Yu, J.W., Yang, M., An, W., Zhao, Y.Y., Lu, N., et al., 2014. Occurrence of odor problems in drinking water of major cities across China. Front. Environ. Sci. Eng. 8 (3), 411-416.

Venkateshwarlu, G., Let, M.B., Meyer, A.S., 2004. Chemical and olfactometric characterization of volatile flavor-compounds in a fish oil enriched milk emulsion.
J. Agric. Food Chem. 52, 311-317.

Watson, S.B., Brownlee, B., Satchwill, T., Hargesheimer, E.E., 2000, Quantitative analysis of trace levels of geosmin and MIB in source and drinking water using headspace SPME. Water Res. 34 (10), 2818-2828.

Watson, S.B., Satchwill, T., Dixon, E., McCauley, E., 2001. Under-ice blooms and source-water odour in a nutrient-poor reservoir: biological, ecological and applied perspectives. Freshw. Biol. 46 (11), 1553-1567.

Watson, S.B., 2003. Cyanobacterial and eukaryotic algal odour compounds: signals or by-products? A review of their biological activity. Phycologia 42 (4), 332-350.

Watson, S.B., Satchwill, T., 2003. Chrysophyte odour production: resource-mediated changes at the cell and population levels. Phycologia 42 (4), 393-405.

Watson, S.B., 2004. Aquatic taste and odor: a primary signal of drinking-water integrity. J. Toxicol. Env. Heal. A 67 (20-22), 1779-1795.

Watson, S.B., 2010. Algal taste and odor. In: Algae: Source to Treatment, first ed. pp. 329-376 Am. Water Works. Ass.

Wee, J.L., Harris, S.A., Smith, J.P., Dionigi, C.P., Millie, D.F., 1994. Production of the taste odor-causing compound, trans-2,cis-6-nonadienal, within the Synurophyceae. J. Appl. Phycol. 6 (4), 365-369.

Wendel, T., Juttner, F., 1996. Lipoxygenase-mediated formation of hydrocarbons and unsaturated aldehydes in freshwater diatoms. Phytochemistry 41 (6) 1445-1449.

Yang, M., Yu, J.W., Li, Z.L., Guo, Z.H., Burch, M., Lin, T.F., 2008. Taihu Lake not to blame for Wuxi's woes. Science 319 (5860), 158-158.

Yu, J.W., Zhao, Y.M., Yang, M., Lin, T.F., Guo, Z.H., Gu, J.N., Li, S., Han, W., 2009 Occurrence of odour-causing compounds in different source waters of China J. Water Supply. Res. Technol. 58 (8), 587-594.

Zaitlin, B., Watson, S.B., Dixon, J., Steel, D., 2003. Actinomycetes in the Elbow River Basin, Alberta, Canada. Water Qual. Res. J. Can. 38 (1), 115-125.

Zhang, K.J., Lin, T.F., Zhang, T.Q., Li, C., Gao, N.Y., 2013. Characterization of typical taste and odor compounds formed by Microcystis aeruginosa. J. Environ. Sci. 25 (8), 1539-1548.

Zhao, Y.Y., Yu, J.W., Su, M., An, W., Yang, M., 2013. A fishy odor episode in a north China reservoir: occurrence, origin, and possible odor causing compounds. J. Environ. Sci. 25 (12), 2361-2366. 